\title{
Performance Research of Improved Switched Inductor Quasi Z Source Fed PMSM Drive
}

\author{
M.Ramakoteswara Rao, K.Soujanya
}

\begin{abstract}
Dynamic: Normal voltage deliver inverter dreams greater circuit to elevate and greenback the yield voltage and present day supply inverter has actually increase potential. To decrease charge and to make form critical, $z$ supply inverter is delivered. which has circulate associated idle elements $(L \& C)$ in supply and inverter. Regardless, it draws broken modern from the facts, and to triumph over this semi $z$ supply inverter is proven, it draws relentless current-day from the records and has incredible boosting limit over $z$ supply inverter. on this company stepped forward traded inductor semi $z$ supply is shown and one of the inductor from the semi $z$ supply inverter is displaced with new topology. It has satisfactory boosting restrict over semi $z$ source. Harmonic width alternate approach is displayed for the trading operation(IGBT). ANFIS (Adaptive Neuro Fuzzy Inference machine) merges fluffy controller and neural framework. Fluffy controller is done on this dare to enhance the manipulate execution of PMSM. The free-torque trends of advanced traded inductor semi $z$ source inverter fed unchanging pmsm are reproduced in this company with the aid of manner of MATLAB(simulnik) and pastime outcomes are differentiated and the semi z-supply energized pmsm power.

Watchwords: Quasi $z$ supply inverter, ANFIS controller, IGBT, PMSM.
\end{abstract}

\section{ADVENT}

Z-supply inverters are progressing topologies that can buck and lift a given information voltage. Each voltage deliver inverter (VSI) and cutting-edge-day source inverter (CSI) have critical issues. To conquer the drawbacks of the ordinary inverter, Z-supply inverter is proposed. An uncommon phase of Z-supply inverter is the shoot thru nation this is done while the store terminals has been shorted a comparative degree leg. An impedance in a Z-supply inverter framework has couple of inductors and couple of capacitors. they're composed alive and nicely that interfaces the important circuit with the DC supply. The Z-deliver inverter can paintings in shoot through and non-shoot through modes. The semi Z-source inverter semi Z-supply inverter is balanced from the Z-source inverter. The semi Zsource inverter has multiple focal factors over the Z-deliver inverter. Inside the semi Z-source inverter, the voltage strain over the switches is dwindled in addition as these switches may be given better elevate restriction. In addition, new topologies are proposed with the extension of separated fragments. In this paper, a Z-supply primarily based absolutely fell $\mathrm{H}$-accomplice inverter is proposed. From splendid styles of taken aback inverters, fell surprised inverter is picked to make a sinusoidal yield waveform and reduce the shopping for and promoting mishaps. One of the most difficult troubles in strength best elements of view is

Revised Manuscript Received on August 19, 2019.

M.Ramakoteswara Rao, PG Scholar, Depratment of EEE CMR College of Engineering \&Technology Kandlakoya, Hyderabad, Telangana (E-mail: ramnani999@gmail.com)

K.Soujanya, Associate Professor, Department of EEE CMR College of Engineering \&Technology Kandlakoya, Hyderabad, Telangana (E-mail: itssoujis@gmail.com) over and completed with both pinnacle and lower gadgets of

the symphonious substance within the electric gadget. usually, sounds can be isolated into kinds they're 1) Voltage track and a pair of 2) modern-day music. By way of the use of a-days, Z-supply inverters (ZSI) which might be the energy tool converters are having numerous vital topologies. The Z-source inverter mainly bases on the buck-help characteristics, this is completed in a low level alternate from dc-cooling. A Z-supply Inverter offer an impedance deliver sort out which is joined with the inverter to a dc data supply, and is associated alive and well which includes capacitors and inductors. The shoot-through(ST) is useful for the development of inverter's enduring best and furthermore in boosting the statistics voltage of Z-deliver inverter. Precisely even as differentiated and other electricity devices converters, the Z-deliver inverter contributes a dc-cooling exchange with excessive functionality of buck-bolster restriction because of much less variety of fragments with lower in fee, quantity. The energy devices, wind generators, photovoltaic (PV) bunches are the strength age topologies, take delivery of an observable profession and along those lines its topologies had extended masses criticalness.

The opportunity of Z-deliver inverter is related to all characterizations of power changes like dc-dc, dc-cooling, cooling and cooling dc. For systems like -stage or amazed they are capable of in like manner be used as present or voltage-advocated Z-supply inverter and function hindrances which realizes lessening profitability of converter, as an instance, moderate-load sports, unidirectional strength movement, immoderate inrush startup contemporary-day, high voltage transversely over capacitor in Z-set up, indifferent supply and a sporadic statistics current. A trendy Z-source inverter's shape is showed up inside the Z-source inverter has relatively charming tendencies like dollar-aid, Z-supply capacitor's voltage stress lessening and excessive inrush startup current.

Z-deliver inverters are another class of inverters proposed with yield voltage or cutting-edge dollar-bolster restrict. however their substantial connecting with extraordinary, there are a few present confinements appeared with the resource of present Z-supply inverters. maximum of which are associated with their want for low guiding precept amount at high commitment to-yield gain, and the closeness of an impedance kind out. The beyond strategies a excessive dc-associate voltage, that can weight the semiconductor, switches senselessly. The very last turns on growth in charge and length, that is undesirable. to decrease the ones stresses, an interesting method is to use appealingly coupled transformers or inductors to raise the growth and 
equalization quantity concurrently, while decreasing the quantity of separated additives required. An examination of the philosophy is proper now acquainted with show off how specific present alluringly coupled inverters can be managed with the aid of utilizing a conventional system. A comparable methodology is then associated with increase even greater appealingly coupled Z-source inverters with crucial focuses that have not been recognized in the composition.

\section{QUASI Z SOURCE INVERTER}

Semi Z-supply inverter (QZSI) is changed form of Zsupply inverter in which there may be differentiate within the impedance set up. rectangular graph depiction of the ZSI is confirmed up in Fig.1.2. It made out of DC deliver, semi framework and inverter. Supply from DC source is given to the semi orchestrate. Consequent to boosting, it's miles given to the inverter and the yield is associated with the shop.

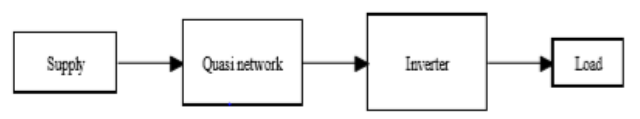

Fig.1 Block diagram of Quasi Z-source inverter

The topology of the five measurement semi Z-source stunned inverter (qZSMLI) is showed up in figure. The qZS framework include two inductors L1 and L2, two capacitors $\mathrm{C} 1$ and $\mathrm{C} 2$, and one diode D1. It has shoot through and nonshoot through states in steady conduction mode. The semi Z-source inverter topology has no shortcomings when appeared differently in relation to the standard Z-source inverter. Both Z-source inverter and semi Z-source inverter beat the issues of the customary voltage source inverter (VSI) and current source inverter (CSI).

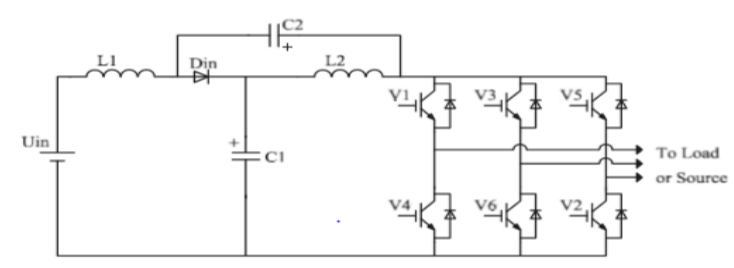

Fig.2 Quasi-Z-source inverter

\section{PERMANENT MAGNET SYNCHRONOUS MOTOR}

Lasting magnet synchronous motor (PMSM) drive system has the advantages of high capability and immense power thickness. It can work in a wide extent of predictable torque and enduring force area to change in accordance with the expanding velocity and quick assignment condition of the electric vehicle. PMSM driver system has transformed into the favored apparatus of various sorts of electric vehicle. Take Pruis, the greatest crossbreed vehicle in the overall market, for example, its key drive motor and starter generator are all PMSM structure. PMSM drive for electric vehicles for the most part embraces voltage source inverter, DC transport voltage is DC control supply voltage.

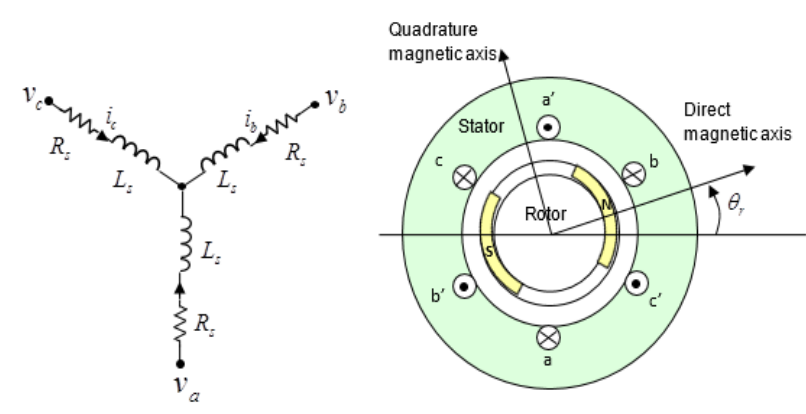

Fig.3. Equivalent circuit for a wye-connected PMSM

The voltage reduces as an alternative at the same time as the battery or superb capacitor discharges at excessive current, will increase basically whilst expenses at high current. Voltage drop will decrease the yield energy and impact the control characteristics. normally, an trade off affiliation is gotten within the motor structure as a manner to grow the amount and weight of the motor.

\section{PROPOSED CONTROL STRATEGY}

Fig. 4 demonstrates the proposed perfect interest D of QZS-IMC consolidated engine vector manipulate shape. The abundancy Uom of yield voltages is gotten with the aid of the square base of the whole of squares of Ud and Uq. with the aid of the usage of then Uom and the information voltage adequacy Uin are sent to the streamlining computation confirmed in section II, which makes the ideal shoot-through commitment cycle D and change list mi of rectifier set up. With the diploma aspect $\theta$ in from the section-shot circle (PLL), they are associated with the alteration of rectifier compose. allow the exchange in accordance with document $m o=1$, by means of then the exchange indication of inverter degree is made, with the degree facet $\theta$ o. Fig.5 demonstrates the flowchart of important manage calculation.

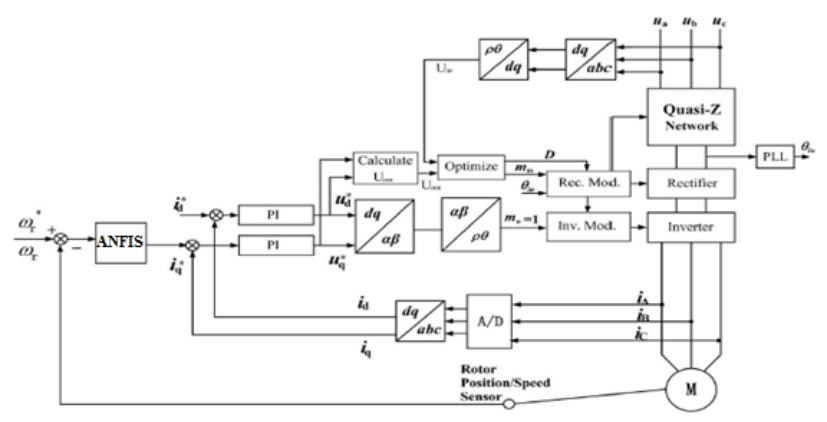

Fig. 4. Proposed optimal $D$ of QZS-IMC based motor vector control structure.

Published By:

Blue Eyes Intelligence Engineering

\& Sciences Publication 


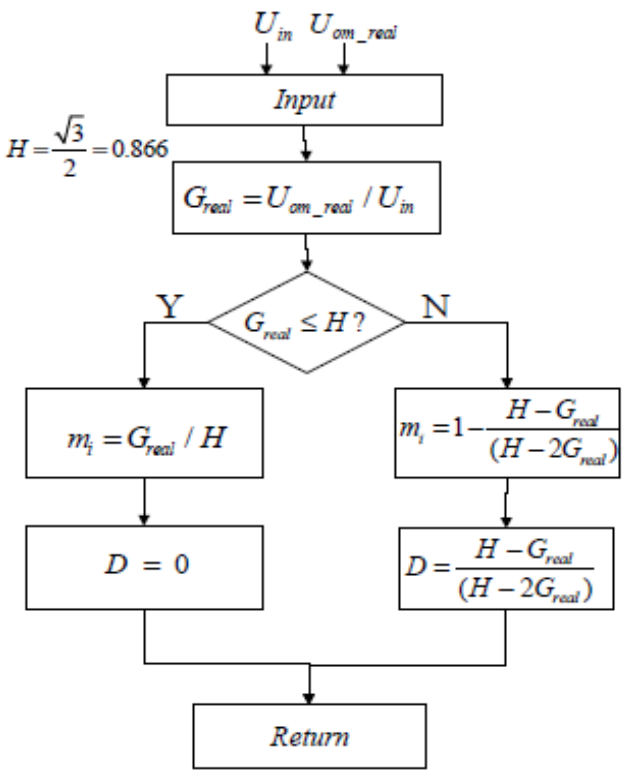

Fig. 5 The basic algorithm for optimizing $D$.

We define the voltage gain of traditional IMC to be

$$
G^{\prime}=\frac{U_{o}}{U_{q z}}=H \times m_{i} \times m_{o} \times \cos \phi_{q z}
$$

The voltage gain of Quasi Z-source network is

$$
\hat{u}_{d c}=U_{C 1}+U_{C 2}=\frac{1}{1-2 D} U_{i n}=B U_{\text {in }}
$$

Where boost factor of quasi $\mathrm{z}$ source network is

$$
B=\frac{U_{q z}}{U_{\text {in }}}=\frac{1}{1-2 \times D}
$$

The peak DC-link voltage of the improved switched inductor quasi Z-source network can be expressed as

$$
\hat{u}_{d c}=U_{C 1}+U_{C 2}=\frac{2}{1-3 D} U_{i n}=B U_{i n}
$$

Where boost factor of improved switched inductor quasi z source network is

$$
B=\frac{2}{1-3 D}
$$

where $\mathrm{D}$ is the shoot-through duty share and B is the carry trouble.

\section{PROPOSED DESIGN OF ADAPTIVE NEURO- FUZZY CONTROLLER}

Bendy neuro fluffy derivation framework (ANFIS) joins the amazing highlights of padded systems and neural frameworks, and it may get the upsides of each in a solitary issue work. ANFIS is a type of phony neural device that depends upon Takagi-sugeno warmness construing structure, that's having one statistics a carried out yield. utilizing a given illuminating rundown, the tool compartment cutoff of ANFIS develops a delicate inferring framework (FIS) even though the participation work parameters are tuned (balanced) utilising a lower lower back impelling estimation. with a view to have a concept of bleeding element ANFIS form for proposed manage, an essential facts is produced the use of number one PI controller and the facts is spared in paintings-area of MATLAB. Through then the ANFIS call for window is opened with the useful resource of making anfis boss in the rule of thumb MATLAB window. Via then the records beginning late spared in paintings-area is stacked within the ANFIS call for window to deliver an stepped forward ANFIS setup as seemed in Fig.6.

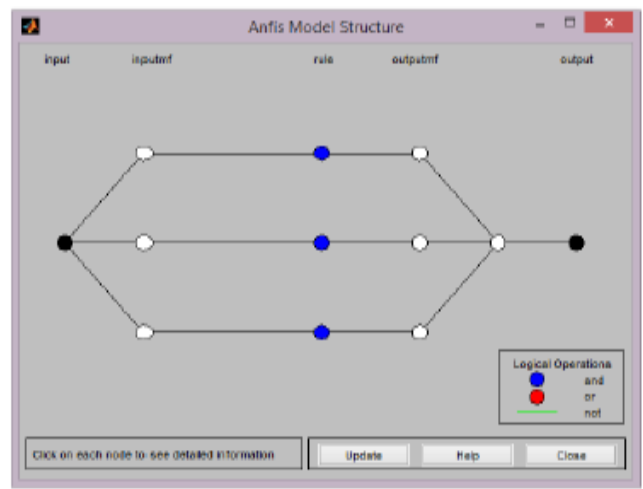

Fig.6. Optimized ANFIS architecture suggested by MATLAB

In Fig.7 shows schematic of the proposed ANFIS based control engineering. The hub elements of each layer inside the ANFIS engineering are depicted as pursues:

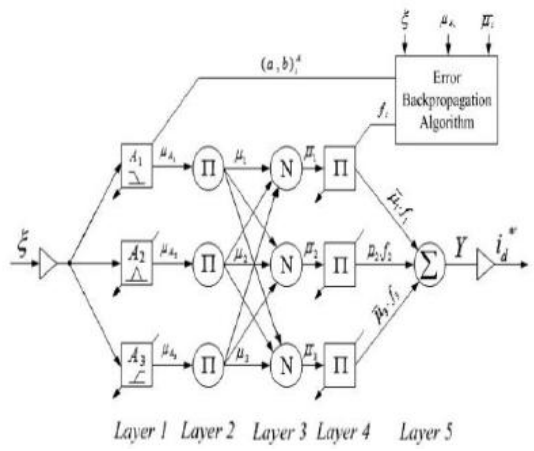

Fig.7. Schematic of the proposed ANFIS-based control architecture.

The variable among reference dc-companion voltage and proper dc-interface voltage $(\xi=\mathrm{Vdc} *-\mathrm{Vdc})$ is given to the neuro-padded controller and a close to mistake is implemented to music the precondition and following parameters [10]. The manage of dc-interface voltage gives the dynamic energy present day place (identity $*^{\prime}$ ), that is moreover changed as regular with check dynamic contemporary-day element mixed from RES (iRen).The focal point issue segments of every layer in ANFIS design are as portrayed underneath:

Layer 1: This deposit is thru and huge referred to as fuzzification layer in which every inside is tended to via the use of rectangular. Right here, three preference factors of confinement are doled out to each datum. The trapezoidal and triangular choice factors of confinement are carried out to decrease the encompass load as regarded in Fig.8.

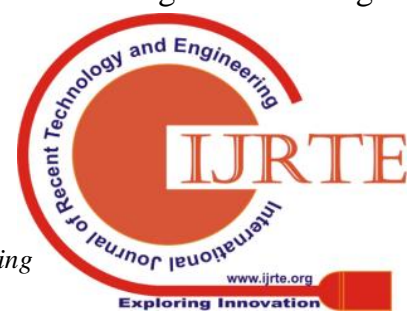


similarly, the seeing recognition factor conditions are as given below:

$$
\begin{aligned}
& \left.\begin{array}{cc}
1 & \varepsilon \leq b_{1} \\
\mu_{A 1}(\varepsilon)=\begin{array}{cc}
z-a_{1} \\
b_{1}-a_{1}
\end{array} \quad b_{1}<\varepsilon<a_{1} & \varepsilon \geq a_{1}
\end{array}\right\} \\
& \left.\mu_{A 2}(\varepsilon)=\begin{array}{cc}
1-\frac{z-a_{1}}{0.5 b_{2}} & \left|\varepsilon-a_{2}\right| \leq 0.5 b_{2} \\
0 & \left|\varepsilon-a_{2}\right| \geq 0.5 b_{2}
\end{array}\right\}
\end{aligned}
$$

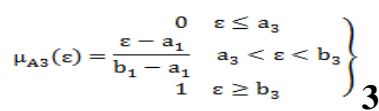

where the guesstimate of parameters (ai, bi) modifications with the adjustment in blunder and as it should be creates the phonetic estimation of each participation paintings. Parameters of this accretion is alluded as begin parameters.

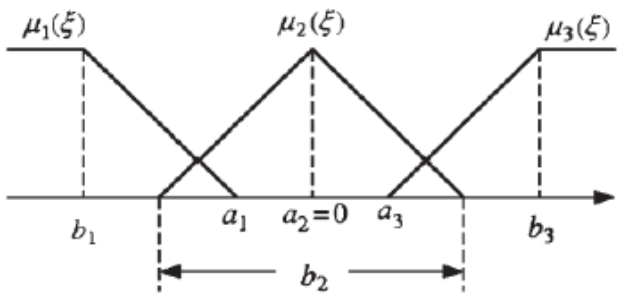

Fig.8 Fuzzy membership functions.

Layer 2: each middle at this accretion is a flow set apart as $\Pi$. which expands the moving toward signs and advances in to the subsequent layer $\mu \mathrm{i}=\mu \mathrm{Ai} \mu \mathrm{Bi}=1,2,3, \ldots$ however for our situation there is high-quality a solitary statistics, in this layer it thoroughly may be left out and the yield of first layer will direct go to the 0.33 layer. right right here, there the produce of each middle communicates to the terminating nature of a stylish.

Layer 3: every hub point on this layer is tended to as circle. this sediment figures the standardized finishing touch nature of each latest as given beneath:

$$
\overline{\mu_{1}}=\frac{\mu_{i}}{\mu_{1}+\mu_{2}+\mu_{3}}
$$

Layer 4: Every node in this layer is a node function

$$
\mathrm{O}_{\mathrm{i}}=\overline{\mu_{1}} \cdot \mathrm{f}_{\mathrm{i}}=\overline{\mu_{1}}\left(\mathrm{a}_{0}^{\mathrm{i}}+\mathrm{a}_{1}^{\mathrm{i}} \varepsilon\right) \mathrm{i}=1,2,3
$$

where the parameters ((ai0ai1) ) are tuned as the capacity of info $(\xi)$. The parameters in this layer are likewise alluded as ensuing parameters.

Layer 5: This layer is likewise called yield layer which registers the yield as given underneath: The yield from this layer is increased with the normalizing element to get the dynamic power current part.

\section{IMPROVED SWITCHED INDUCTOR QUASI Z-} SOURCE SIMULATION RESULTS

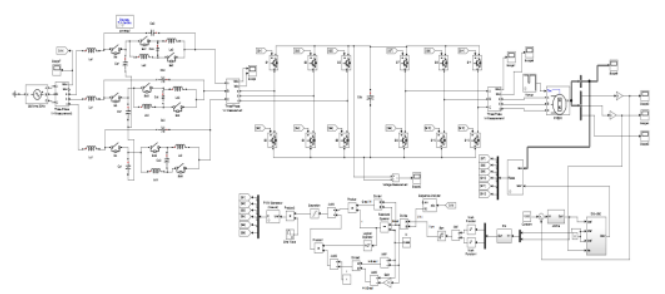

Fig.9 MATLAB/SIMULINK diagram of the ISQZS-IMC based motor vector control structure with ANFIS controller

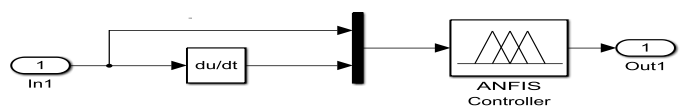

Fig.10 ANFIS controller subsystem

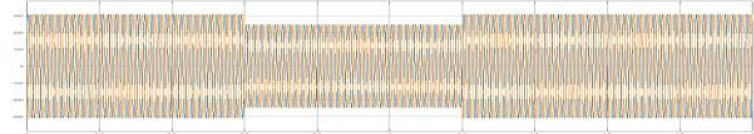

Fig.11 Input power supply voltages

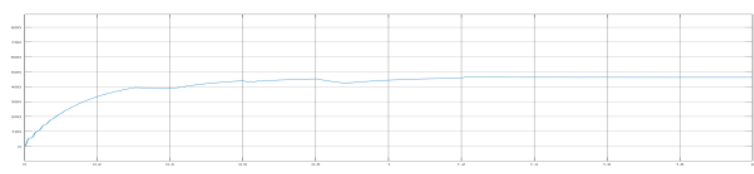

Fig.12 Dc bus voltage

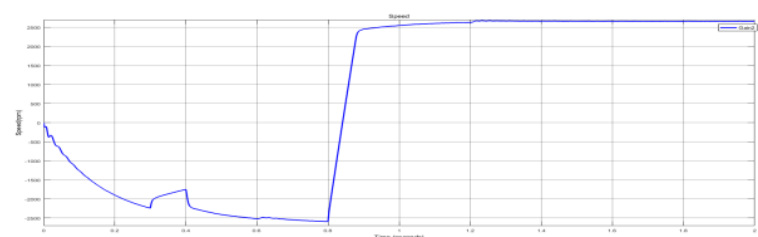

Fig.13 Motor speed

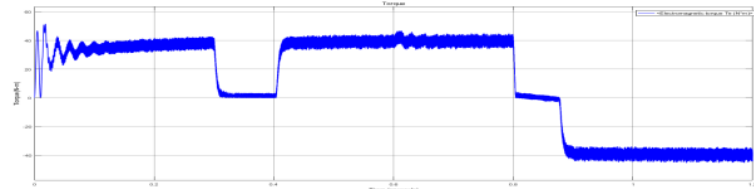

Fig .14 Motor torque

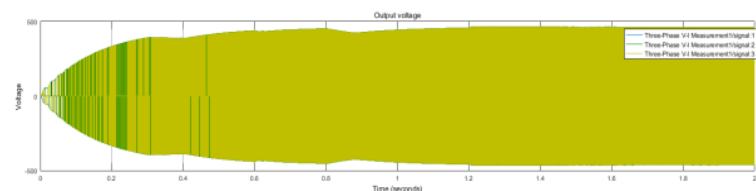

Fig.15 Inverter output voltage

Table 1.Comparison of results

\begin{tabular}{|c|c|c|}
\hline Parameters & $\begin{array}{c}\text { Quasi z source fed } \\
\text { PMSM }\end{array}$ & $\begin{array}{c}\text { Improved SI- QZS } \\
\text { fed PMSM }\end{array}$ \\
\hline Speed & $1200 \mathrm{rpm}$ & $2550 \mathrm{rpm}$ \\
\hline Torque & $40 \mathrm{Nm}$ & $40 \mathrm{Nm}$ \\
\hline
\end{tabular}

\section{CONCLUSION}

On this assignment, advanced traded inductor semi $\mathrm{Z}$ deliver is found out to control and to boom speed of consistent magnet synchronous motor, with developing voltage boosting adequacy to make the present relentless by using with ANFIS primarily based ISIQZS-IMC. The ANFIS systems managing progressively complex parameters, which demonstrates the reasonability of the 
startling series of pace (due to parametric collection) from the identical antique regard (PI) and its consequences on the diverse parameters, (as an example, slip, modern-day, torque, and so on.) to gain the solidness. The execution of the rate and torque capabilities of the advanced traded inductor semi $\mathrm{z}$ supply energized in no way-finishing magnet synchronous motor power are destitute someplace round D streamlining figuring which improves the motor speed, DC transport voltage and yield voltage over the heap contrasting and Quasi $\mathrm{z}$ supply strengthened pmsm. The undertaking consequences for engine velocity with ANFIS may be re advanced by way of MATLAB/SIMLINK.

\section{REFERENCES}

1. Mingzhu Guo, Yushan Liu, Shuo Liu, Ning Nie, "excessive overall performance Operation control of Quasi-ZSource based totally everlasting Magnetic Synchronous Motor force", 2018 IEEE twelfth worldwide conference on Compatibility, strength Electronics and strength Engineering (CPEPOWERENG 2018), 10-12 April 2018.

2. Serhii Stepenko, Carlos Roncero-Clemente, Oleksandr Husev, Elena Makovenko, Sergio Pires Pimentel, Dmitri Vinnikov, "New Interleaved unmarried-segment Quasi-Z-source Inverter with energetic power Decoupling", 2018 IEEE twelfth international conference on Compatibility, electricity Electronics and power Engineering (CPE-POWERENG 2018), 07 June 2018.

3. Three.Mohamed Trabelsi, Haitham Abu-Rub, Baoming Ge, "1-MW Quasi-Z-supply based Multilevel PV power Conversion machine", 2016 IEEE global convention on industrial technology (ICIT), 14-17 March 2016.

4. Yushan Liu, Member, IEEE, Haitham Abu-Rub, Fellow, IEEE, Yichang Wu, Khalid Ahamed Ghazi, "structure of SiCbased absolutely unmarried-segment Quasi-Z-supply Inverter", 2018 IEEE 12th international conference on Compatibility, power Electronics and electricity Engineering (CPE-POWERENG 2018), 10-12 April 2018.

5. Yuba Raj Kafle, Graham E metropolis, "excessive performance Shoot-thru Modulation technique for QuasiZSource DC/DC Converters", PCIM Europe 2018; global Exhibition and convention for electricity Electronics, smart movement, Renewable energy and energy control, five-7 June 2018.

6. Mohammad Mehdi, Haji-Esmaeili, Ebrahim Babaei, and Mehran Sabahi, "excessive Step-Up Quasi-Z deliver DC-DC Converter", IEEE Transactions on electricity Electronics, quantity: 33, difficulty: 12 December 2018.

7. Minh-Khai Nguyen, Member, IEEE, Truong-Duy Duong, young-Cheol Lim, Member, IEEE, and Joon-Ho Choi, Member IEEE, "high Voltage advantage Quasi-Switched beautify Inverters with Low enter current Ripple", IEEE Transactions on commercial Informatics, 23 February 2018.

8. Eight.Mohamed Trabelsi, Panagiotis Kakosimos, Hasan Komurcugil, "manipulate of Grid Voltage Disturbances the use of Quasi Z deliver based totally Dynamic Voltage Restorer", 2018 IEEE 12th worldwide convention on Compatibility, power Electronics and electricity Engineering (CPE-POWERENG 2018), 10-12 April 2018.

9. Nine.Taher Ahmadzadeh, 1Ebrahim Babaei, Senior Member, "superior Quasi-Z-supply based totally three-phase three degree neutral issue Clamped Inverter", 2018 ninth Annual power Electronics, Drives systems and technology conference (PEDSTC), thirteen-15 February 2018.

10. Mohamed Meraj, Syed Rahman and Shahbaz Husain, Lazhar Ben-Brahim, Atif Iqbal, "New Switching technique for QuasiZ-source Resonant converter", 2018 IEEE twelfth global conference on Compatibility, power Electronics and energy Engineering (CPE-POWERENG 2018), 10-12 April 2018.
11. Eleven.Minh-Khai Nguyen, Tan-Tai Tran, and younger-Cheol Lim "A family of PWM manage techniques for single-section Quasi Switched increase Inverter", IEEE Transactions on energy Electronics, 30 April 2018.

12. .Negar Noroozi, Mokhtar Yaghoubi, and MohamReza Zolghadri, "A Modulation method for Leakage present day discount in a 3-section Grid-Tie Quasi-Z-supply Inverter", IEEE Transactions on electricity Electronics, 04 September 2018.

13. Rui Wang, Xu Jia, Shuai Dong, Qianfan Zhang, "PMSM the usage of system format for electric powered powered automobile programs trouble to Bi-directional Quasi-Z-supply Inverter", 2018 13th IEEE convention on commercial Electronics and packages(ICIEA), 31 may additionally - 2 June 2018.

14. Tomasz Gajowik, Kamil Możdżyński, Mariusz Malinowski, Khalid Ghazi, Haitam Abu-Rub, "SiC Mosfet as opposed to Si IGBT based totally H-Bridge semi Z-source converter", 2018 IEEE twelfth international conference on Compatibility, electricity Electronics and energy Engineering (CPEPOWERENG 2018), 10-12 April 2018.

15. Anish Ahmad, Vinod Kumar Bussa, R. k. Singh, and R. Mahanty, "Traded raise changed Z-deliver Inverter Topologies with advanced Voltage benefit functionality", IEEE magazine of rising and decided on subjects in electricity Electronics, 05 April 2018.

16. Duc-Tri Do, Minh-Khai Nguyen, Member, IEEE, "3-level Quasi-Switched enhance T-type Inverter: evaluation, PWM manipulate, and Verification", IEEE Transactions on commercial Electronics, volume: sixty five, problem: 10, Oct. 2018, 23 January 2018. 